\title{
Thyrotropin-releasing Hormone Can Relieve Cancer-related Fatigue: Hypothesis and Preliminary Observations

\author{
J Kamath, ${ }^{1}$ GG Yarbrough, ${ }^{2}$ AJ Prange JR ${ }^{3}$ And A Winokur ${ }^{1}$ \\ ${ }^{1}$ Department of Psychiatry, University of Connecticut Health Center, Farmington, \\ Connecticut, USA; ${ }^{2}$ TRH Therapeutics, Portland, Oregon, USA; ${ }^{3}$ Department of Psychiatry, \\ University of North Carolina, Chapel Hill, North Carolina, USA
}

Fatigue in cancer patients is highly prevalent, predominantly idiopathic, difficult to manage, and has a significant negative impact on quality of life. Thyrotropin-releasing hormone (TRH) exerts normotrophic, state-dependent therapeutic effects in a variety of experimental and clinical situations. To evaluate TRH as a treatment for cancerrelated fatigue, an ongoing randomized, placebo-controlled, crossover pilot study of breast cancer patients has been initiated and this report presents preliminary observations conducted with three of these patients over 4 consecutive weeks, thereby involving a total of six TRH treatments and six saline controls. Global assessment using both subjective and objective parameters showed that TRH exerted clear anti-fatigue effects in four of the six TRH treatments. These responses were rapid in onset and persisted through the $24 \mathrm{~h}$ observation period. No anti-fatigue responses were seen in five of the six saline controls. No unexpected side-effects were seen with TRH administration. These initial findings support the proposal that TRH can ameliorate cancer-related fatigue.

\section{KEY WORDS: Thyrotropin-RELEASING HORMONE; CANCER-RELATED FATIGUE; BREAST CANCER;}

\section{HoMeOSTASIS}

\section{Introduction}

Fatigue is the most common symptom of cancer and cancer treatments. ${ }^{1}$ It is exceedingly debilitating and may persist for months or even years after completion of treatment. $^{2}$ Frequently accompanied by comorbidities, such as depression or pain, cancer-related fatigue is sometimes associated with underlying contributory factors such as anemia, electrolyte abnormalities or hypothyroidism. ${ }^{3}$ In most patients, however, specific causative factors cannot be identified. This idiopathic fatigue is often profound, persistent and invariably unrelieved by rest. ${ }^{4}$ To date, no therapeutic intervention has been shown to be reliably effective. ${ }^{5}$

Cancer-related fatigue can be viewed as a failure of homeostasis. It has been associated with a cascade of interrelated changes in the neuroendocrine system, central/peripheral nervous system, neurotransmitter metabolism and circadian rhythms. ${ }^{6,7}$ Additionally, existing evidence suggests that 
fatigue in cancer patients is associated with immune dysfunction and may be due to the actions of various pro-inflammatory cytokines released as a result of the disease process as well as in response to radiation and/or chemotherapeutic treatment interventions. ${ }^{8}$

As first proposed in 2003, thyrotropinreleasing hormone (TRH; pGlu-His-ProNH ${ }_{2}$ ) is thought to be widely involved in the control of behavioral, metabolic and immunological homeostasis. ${ }^{9}$ - 11 This teleologically-based understanding of the fundamental role of TRH is consonant with its ubiquitous distribution and its involvement in many physiological processes, above and beyond its neuroendocrine functions. ${ }^{9}$ Moreover, this unifying hypothesis provides insight into the basis of the widely reported, diverse and nondisease-specific therapeutic effects of TRH and TRH-mimetic analogs. ${ }^{10}$ Thus, in various clinical situations and disease states TRH agonism exerts normotrophic, statedependent therapeutic effects which manifest as restorations of homeostasis, including that of the immune system. ${ }^{11}$ In instances of behavioral depression, TRH agonism exerts arousing and analeptic actions. Additionally, TRH can counteract various immune dysfunctions known to be associated with cancer-related fatigue. ${ }^{11}$

In light of the above considerations, it was hypothesized that TRH agonism should ameliorate cancer-related fatigue. ${ }^{11}$ To assess this possibility, a pilot trial has been set up to examine the effects of TRH on fatigue in breast cancer patients.

\section{Patients and methods PATIENT CHARACTERISTICS}

Informed consent was obtained in writing from each participant. Patients with breast cancer who were experiencing cancer-related fatigue according to the criteria of the International Classification of Diseases 10th Revision (ICD-10) ${ }^{12,13}$ were eligible for inclusion in the study. Patients were also required to have a score of $<34$ on the Functional Assessment of Cancer Therapy (FACT)-Fatigue scale ${ }^{14}$ at the initial evaluation. Patients with clearly identifiable but untreated causes of fatigue (e.g. anemia) were excluded, as were patients with any unstable and clinically significant psychiatric or substance use disorders, and those with a history of cardiovascular disease. Patients with comorbidities (e.g. depression, insomnia) were included if the comorbid factors were not judged to be the main causative factors of fatigue.

\section{STUDY DESIGN}

This pilot phase II trial employed a doubleblind, placebo-controlled, crossover design with two randomizations (www.Clinical Trials.gov identifier NCT00790296). Patients were assessed for fatigue $1 \mathrm{~h}$ before and 3, 7, and $24 \mathrm{~h}$ after intravenous administration of TRH (either 0.5 or $1.5 \mathrm{mg}$ ) or saline placebo. This procedure was performed once weekly over 4 consecutive weeks, resulting in a total of six TRH treatments and six controls (Fig. 1).

The primary outcome measure was the visual analog scale for energy level (VAS-E) ${ }^{14}$ as assessed by the subject. Other outcome measures included the multidimensional fatigue inventory, ${ }^{15}$ functional assessment using a 6-min walk test ${ }^{16}$ and a quality of life assessment using the FACT-General questionnaire. ${ }^{17}$ Comorbid factors were evaluated using the modified, four-item Leeds Sleep Evaluation Questionnaire, ${ }^{18}$ the Hospital Anxiety and Depression questionnaire $^{19}$ and the 65-item Profile of Mood States questionnaire. ${ }^{20}$ A blinded clinician rated fatigue status and general quality of life using the Clinical Global 


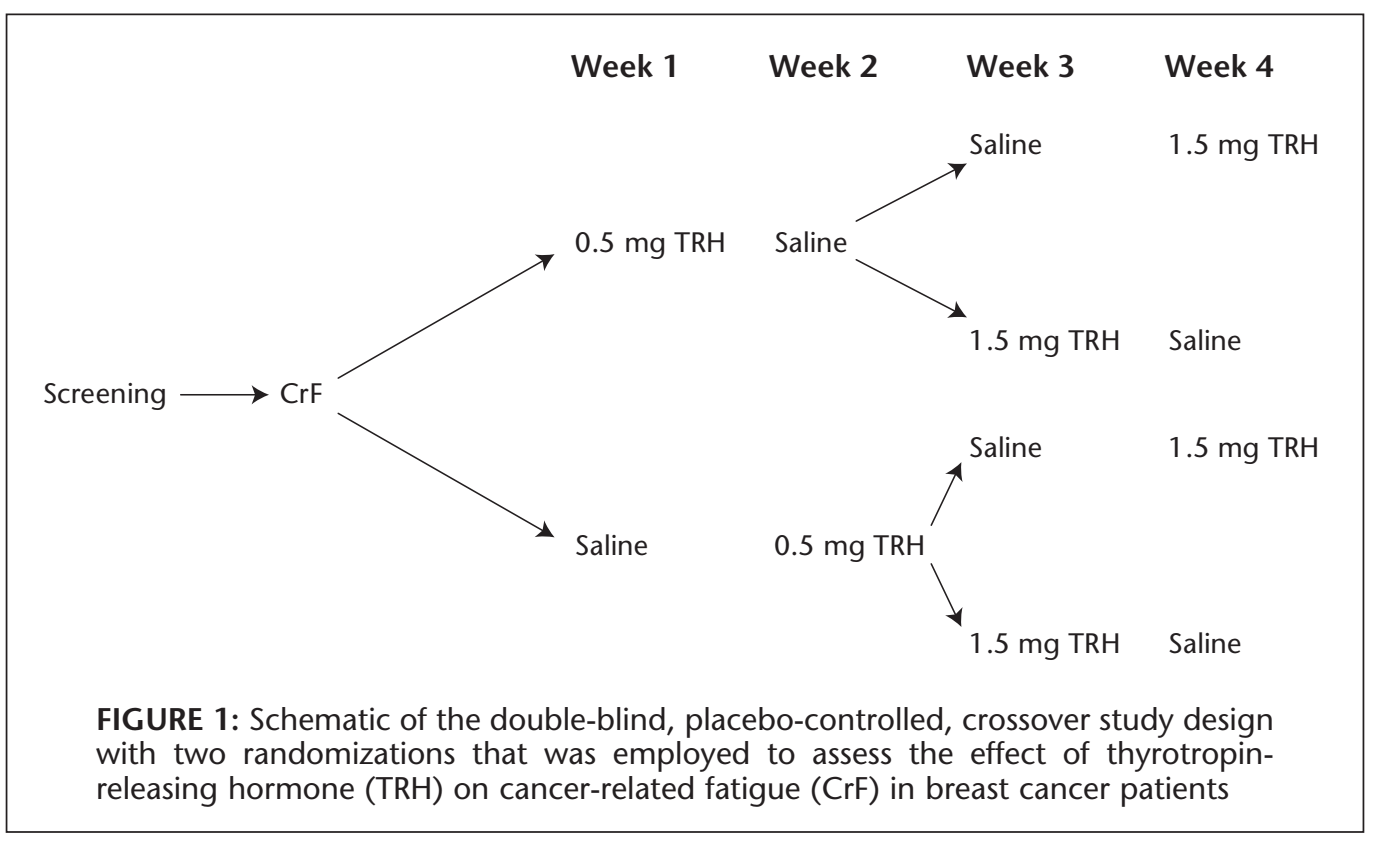

Impression (CGI) scale before and after administration of study medication.

The study protocol was approved by the University of Connecticut Health Center Institutional Review Board. All study procedures were conducted in accordance with an Investigational New Drug application (IND 72,351) approved by the Food and Drug Administration of the USA.

\section{Results}

To date, three patients have each received two injections of saline and two injections of TRH $(0.5$ and $1.5 \mathrm{mg})$ in accordance with the crossover study treatment schedule, giving a total of six TRH treatments and six controls. All three patients were in remission and had completed cancer treatments at least 2 years (range $2-5$ years) before the study. No clinically relevant medical or psychiatric comorbidities were noted in any of the patients.

Data on the overall positive (+) antifatigue or negative (-) no anti-fatigue responses to each of the six TRH treatments and six controls are presented in Table 1. This shows the combined assessments of the subjective primary outcome measure (VAS-E score) plus the objective walking test results and observations by an observer blinded to the treatments and represent our qualitative global assessments of each patient's response to each treatment. The change in VAS-E scores at 3, 7, and $24 \mathrm{~h}$ show that the antifatigue related effects of TRH remained evident through the $24 \mathrm{~h}$ observation period after dosing (Table 1).

In four of the six TRH treatments, clear anti-fatigue responses were seen. These responses became evident $3-7 \mathrm{~h}$ after dosing, persisted through the $24 \mathrm{~h}$ observation period and were reported as considerable and robust by the patients. Possible dose-response effects of TRH were not evident in these limited data. In patient II with treatment 3 (week 3), no response to TRH was seen, however, at that time the patient was not clearly fatigued, which conceivably might be ascribed to a carryover effect from the TRH treatment received $a$ 


\begin{tabular}{|c|c|c|c|c|}
\hline \multirow[b]{2}{*}{ Patient/Assessment } & \multicolumn{4}{|c|}{ Treatment/Week } \\
\hline & 1 & 2 & 3 & 4 \\
\hline Patient I & TRH $0.5 \mathrm{mg}$ & Saline ${ }^{a}$ & TRH 1.5 mg & Saline ${ }^{a}$ \\
\hline \multicolumn{5}{|l|}{ Change in VAS- $\mathrm{E}^{\mathrm{C}}$} \\
\hline $3 \mathrm{~h}$ & $+/-$ & - & $+/-$ & - \\
\hline $7 \mathrm{~h}$ & + & - & + & - \\
\hline $24 \mathrm{~h}$ & + & - & + & - \\
\hline Globald $^{d}$ & + & - & + & - \\
\hline Patient II & Saline & TRH $0.5 \mathrm{mg}$ & TRH $1.5 \mathrm{mg}^{\mathrm{b}}$ & Saline \\
\hline \multicolumn{5}{|l|}{ Change in VAS- $\mathrm{E}^{\mathrm{C}}$} \\
\hline $3 \mathrm{~h}$ & - & $+/-$ & - & - \\
\hline $7 \mathrm{~h}$ & - & + & - & - \\
\hline $24 \mathrm{~h}$ & $+/-$ & + & - & + \\
\hline Globald $^{\mathrm{d}}$ & - & + & - & $+/-$ \\
\hline Patient III & TRH $0.5 \mathrm{mg}$ & Saline & Saline & TRH $1.5 \mathrm{mg}$ \\
\hline \multicolumn{5}{|l|}{ Change in VAS- $\mathrm{E}^{\mathrm{C}}$} \\
\hline $3 \mathrm{~h}$ & + & + & - & + \\
\hline $7 \mathrm{~h}$ & + & + & - & + \\
\hline $24 \mathrm{~h}$ & + & + & - & + \\
\hline Globald $^{d}$ & $+/-$ & + & - & + \\
\hline
\end{tabular}

${ }^{a}$ Modest increase in fatigue noted.

bIn this patient no fatigue was evident in week 3 at baseline perhaps as a consequence of previous TRH exposure at week 2.

'Change in VAS-E was calculated by comparing scores to baseline ( $1 \mathrm{~h}$ prior to study medication administration) and was considered a positive anti-fatigue response $(+)$ if the change in VAS-E score was $\geq 25 \%$ compared with baseline; - , no change from baseline; $+/-,<25 \%$ change from baseline.

${ }^{\mathrm{d}} \mathrm{Global}$ assessment of the response represents the combined assessments of the subjective visual analog scale for energy level (VAS-E) scores 3, 7, and $24 \mathrm{~h}$ after treatment compared with the $1 \mathrm{~h}$ pre-treatment baseline and patient comments plus the objective walk test results and the observations of an observer blinded to the treatments: + , overall positive anti-fatigue response, including $\geq 25 \%$ increase in VAS-E score compared with baseline; -, no anti-fatigue response; $+/-$, equivocal, unclear response, including slight increase in VAS-E score.

week earlier. In patient III with treatment 1 (week 1), only a tendency (+/-) towards improvement was discerned after administration of $0.5 \mathrm{mg} \mathrm{TRH}$. Transient, modest increases in blood pressure and heart rate were the main (and expected) sideeffects $^{21}$ after TRH administration. No unexpected side-effects were noted.

Among the six placebo infusion trials, a clear anti-fatigue response was noted only in patient III with treatment 2 (week 2). For another placebo infusion trial, no clear conclusions could be adduced from patient II with treatment 4 (week 4). Saline injections produced no anti-fatigue effects in the other four placebo infusion trials.

\section{Discussion}

Despite the widely documented high prevalence of cancer-related fatigue and its impact on quality of life, effective interventions for this debilitating condition remain elusive. ${ }^{4}$ Evidence for nonpharmacological relief of cancer-related 
fatigue is largely idiosyncratic and anecdotal. $^{22}$ Pharmacological interventions, as judged by recent trials with stimulants, have failed to show efficacy in randomized, placebo-controlled studies. ${ }^{23-27}$

The present data show that TRH had a positive effect on the global assessment of fatigue in three breast cancer patients. Overall, predicted responses (i.e. positive anti-fatigue effects in response to TRH or no response to saline or to TRH in a nonfatigued state) were noted in nine $(75 \%)$ of the 12 tests, equivocal responses were seen in two and one clear, not-predicted anti-fatigue placebo response was observed. Of note, $\mathrm{TRH}$, like other bioactive neuropeptides, is known to have a plasma half-life of only a few minutes, ${ }^{11}$ yet the anti-fatigue related effects remained evident through the $24 \mathrm{~h}$ observation period after dosing in the present study. The basis for this apparent pharmacokinetic-pharmacodynamic discordance is not understood; however, it should be noted that long term effects of TRH administration have been seen in other studies. Specific examples include electroencephalographic changes observed with TRH administration lasting $24 \mathrm{~h}^{28}$ and anti-fatigue effects of TRH administration lasting $24 \mathrm{~h}$ or longer in a study conducted in patients with bipolar depression. ${ }^{29}$ Although preliminary and limited, these observations are consistent with the hypothesis that TRH can relieve fatigue in cancer patients. Furthermore, these apparent therapeutic effects can be understood in the context of the normotrophic, homeostasis-promoting actions of TRH agonism ${ }^{9-11}$ and may relate to interactions of TRH with proinflammatory cytokines. ${ }^{11}$

Clearly, more data are needed to substantiate these findings and mechanistic speculations. Nonetheless, they may portend significant medical benefit. Enrolment in the present study is continuing and it is hoped that others will endeavour to evaluate and extend these observations.

\section{Acknowledgments}

We gratefully acknowledge the Susan G Komen Foundation (grant No. BCTR 0601182), the Hollfelder Foundation, the General Clinical Research Center at the University of Connecticut Health Center (National Institutes of Health grant No. M01 RR06192) and the Dr Manfred J Sakel Distinguished Chair in Psychiatry Fund for support of this study.

\section{Conflicts of interest}

GGY, AJP Jr, and AW are members of TRH Therapeutics LLC, an Oregon-based consulting organization which holds a USA patent $(\# 7,462,595)$ on the use of TRH and related peptidomimetics to relieve cancerrelated fatigue.

- Received for publication 18 May 2009 • Accepted subject to revision 21 May 2009

- Revised accepted 10 August 2009

Copyright @ 2009 Field House Publishing LLP

\section{References}

1 Hofman M, Ryan JL, Figueroa-Moseley CD, et al: Cancer-related fatigue: the scale of the problem. Oncologist 2007; 12(suppl 1): 4 - 10.

2 Bower JE, Ganz PA, Desmond KA, et al: Fatigue in long-term breast cancer survivors: a longitudinal investigation. Cancer 2006; 106: $751-758$.

3 Mock V, Atkinson A, Barsevick A, et al: NCCN practice guidelines for cancer-related fatigue. Oncology (Williston Park) 2000; 14: 151 - 161.

4 Stone PC, Minton O: Cancer-related fatigue. Eur J Cancer 2008; 44: 1097 - 1104.

5 Carroll JK, Kohli S, Mustian KM, et al: Pharmacological treatment of cancer-related fatigue. Oncologist 2007; 12(suppl 1): 43 - 51.

6 Miller AH, Ancoli-Israel S, Bower JE, et al: Neuroendocrine-immune mechanisms of 
behavioural comorbidities in patients with cancer. J Clin Oncol 2008; 26: 971 - 982.

7 Payne JK: A neuroendocrine-based regulatory fatigue model. Biol Res Nurs 2004; 6: 141 - 150.

8 Schubert C, Hong S, Natarajan L, et al: The association between fatigue and inflammatory marker levels in cancer patients: a quantitative review. Brain Behav Immun 2007; 21: 413 - 417.

9 Gary KA, Sevarino KA, Yarbrough GG, et al: The thyrotropin-releasing hormone (TRH) hypothesis of homeostatic regulation: implications for TRH-based therapeutics. I Pharmacol Exp Ther 2003; 305: 410 - 416.

10 Yarbrough GG, Kamath J, Winokur A, et al: Thyrotropin-releasing hormone (TRH) in the neuroaxis: therapeutic effects reflect physiological functions and molecular actions. Med Hypotheses 2007; 69: 1249 - 1256.

11 Kamath J, Yarbrough GG, Prange AJ, et al: The thyrotropin-releasing hormone (TRH)-immune system homeostatic hypothesis. Pharmacol Ther 2009; 21: 20 - 28.

12 Portenoy RK, Itri LM: Cancer-related fatigue: guidelines for evaluation and management. Oncologist 1999; 4: 1 - 10.

13 World Health Organization (WHO): International Classification of Diseases 10th Revision (ICD-10). Geneva: WHO, 1997 (updates to 2008) (available at http://www.who.int/ classifications/icd/en).

14 Van Belle S, Paridaens R, Evers G, et al: Comparison of proposed diagnostic criteria with FACT-F and VAS for cancer-related fatigue: proposal for use as a screening tool. Support Care Cancer 2005; 13: 246 - 254.

15 Smets EM, Garssen B, Bonke B, et al: The Multidimensional Fatigue Inventory (MFI) psychometric qualities of an instrument to assess fatigue. J Psychosomat Res 1995; 39: 315 325.

16 Enright PL: The six-minute walk test. Respir Care 2003; 48: 783 - 785 .

17 Cella DF, Tulsky DS, Gray G, et al: The Functional Assessment of Cancer Therapy scale: development and validation of the general measure. J Clin Oncol 1993; 11: 570 579.

18 Parrott AC, Hindmarch I: The Leeds Sleep Evaluation Questionnaire in psychopharmacological investigation - a review.
Psychopharmacology 1980; 71: 173 - 179.

19 Zigmond AS, Snaith RP: The hospital anxiety and depression scale. Acta Psychiatr Scand 1983; 67: $361-370$.

20 McNair DM, Lorr M, Droppleman LF: Manual: Profile of Mood States. San Diego: Educational and Industrial Testing Service, 1981.

21 Mellow AM, Sunderland T, Cohen RM, et al: Acute effects of high-dose thyrotropin-releasing hormone infusions in Alzheimer's disease. Psychopharmacology 1989; 98: 403 - 407.

22 Markes M, Brockow T, Resch KL: Exercise for women receiving adjuvant therapy for breast cancer. Cochrane Database Syst Rev 2006; 18: CD005001.

23 Mar Fan HG, Clemons M, Xu W, et al: A randomized, placebo-controlled, double-blind trial of the effects of d-methylphenidate on fatigue and cognitive dysfunction in women undergoing adjuvant chemotherapy for breast cancer. Support Care Cancer 2008; 16: 577 - 583.

24 Bruera E, Valero V, Driver L, et al: Patientcontrolled methylphenidate for cancer fatigue: a double-blind, randomized, placebo-controlled trial. J Clin Oncol 2006; 24: 2073 - 2078.

25 Butler JM Jr, Case LD, Atkins J, et al: A phase III, double-blind, placebo-controlled prospective randomized clinical trial of d-threomethylphenidate $\mathrm{HCl}$ in brain tumor patients receiving radiation therapy. Int I Radiat Oncol Biol Phys 2007; 69: 1496 - 1501.

26 Roscoe JA, Morrow GR, Hickok JT, et al: Effect of paroxetine hydrochloride (Paxil) on fatigue and depression in breast cancer patients receiving chemotherapy. Breast Cancer Res Treat 2005; 89: 243 - 249.

27 Bruera E, El Osta B, Valero V, et al: Donepezil for cancer fatigue: a double-blind, randomized, placebo-controlled trial. J Clin Oncol 2007; 25: 3475 - 3481.

28 Itil TM, Patterson CD, Polvan N, et al: Clinical and CNS effects of oral and I.V. thyrotropinreleasing hormone in depressed patients. Dis Nerv Syst 1975; 36: 529 - 536.

29 Szuba MP, Amsterdam JD, Fernando III AT, et al: Rapid antidepressant response after nocturnal TRH administration in patients with bipolar type I and bipolar type II major depression. J Clin Psychopharmacol 2005; 25: 325 $-330$.

Author's address for correspondence

\section{Dr Jayesh Kamath}

Department of Psychiatry, University of Connecticut Health Center, 263 Farmington

Avenue, Farmington, CT 06030, USA.

E-mail: jkamath@uchc.edu 